\title{
The Comparative Economic Burden of Mild, Moderate, and Severe Fibromyalgia: Results from a Retrospective Chart Review and Cross-Sectional Survey of Working-Age U.S. Adults
}

\author{
Arthi Chandran, MS, MPH; Caroline Schaefer, MBA; Kellie Ryan, MPH; \\ Rebecca Baik, BS; Michael McNett, MD; and Gergana Zlateva, PhD
}

\begin{abstract}
BACKGROUND: Patients with fibromyalgia report persistent widespread pain, fatigue, and substantial functional limitations, which may lead to high health resource use (HRU) and lost productivity. Previous analyses of the U.S. population have not examined the direct and indirect costs of fibromyalgia by severity level.
\end{abstract}

OBJECTIVES: To assess (a) HRU, direct and indirect costs associated with fibromyalgia in routine clinical practice in the United States using a patientcentric approach, and (b) the relationship of fibromyalgia severity level to HRU and costs.

METHODS: This study recruited a nonprobability convenience sample of 203 subjects aged 18 through 65 years between August 2008 and February 2009 from 20 U.S. community-based physician offices. Subjects had a prior diagnosis of fibromyalgia by a rheumatologist, neurologist, or pain specialist; received treatment at the enrolling physician's practice for at least 3 months; experienced widespread pain for at least 3 months; and experienced pain in the previous 24 hours. Subjects completed a 106-item patient questionnaire that included 5 validated health-related quality-of-life instruments and study-specific questions about demographics; clinical history; overall health; treatment satisfaction; and impact of fibromyalgia on cognitive function, daily activities, and employment status. Subjects also self-reported hours of unpaid informal caregiver time because of inability to perform daily activities (e.g., housework, child care), out-of-pocket expenses for medical and nonmedical services, and lost productivity related to fibromyalgia for the previous 4 weeks. The 20 -item Fibromyalgia Impact Questionnaire total score was used to stratify subjects into fibromyalgia severity groups ( 0 to less than $39=$ mild, 39 to less than $59=$ moderate, 59 to $100=$ severe). Staff at each site recorded clinical characteristics, HRU, and medication use attributable to fibromyalgia on a paper clinical case report form (CRF) based on a 3-month retrospective medical chart review. Unit costs for 2009 were assigned to the 3-month HRU data reported on the CRF and 4-week subject-reported lost productivity. Costs were then annualized and reported in the following categories: direct medical, direct nonmedical, and indirect. Differences across severity levels were evaluated using the Kruskal-Wallis test (continuous measures) and Pearson chi-square or Fisher's exact tests (categorical measures) at the 0.05 alpha level.

RESULTS: Of the 203 subjects, 21 (10.3\%) had mild, 49 (24.1\%) had moderate, and $133(65.5 \%)$ had severe fibromyalgia. For subjects with mild, moderate, and severe fibromyalgia, respectively, the number of fibromyalgia-related medications (3-month means: 1.8, 2.3, and 2.8, $P=0.011)$ and office visits to health care providers (3-month means: 2.7 , 5.2 , and $6.9, P<0.001$ ) significantly differed across severity levels. Across severity levels, total medical and nonmedical out-of-pocket costs also differed $(P=0.025)$. Mean [median] 3-month total direct costs (including payer costs for HRU and out-of-pocket costs for medical and nonmedical services) were $\$ 1,213[\$ 1,150], \$ 1,415[\$ 1,215]$, and $\$ 2,329[\$ 1,760]$ for subjects with mild, moderate, and severe fibromyalgia, respectively $(P=0.002)$; and mean [median] 3-month indirect costs (including subjectreported absenteeism, unemployment, disability, and the estimated value of unpaid informal care) were $\$ 1,341$ [ $\$ 0], \$ 5,139$ [\$1,680], and $\$ 8,285$ $[\$ 7,030](P<0.001)$. Mean total indirect costs accounted for $52.5 \%, 78.4 \%$, and $78.1 \%$ of mean total costs for subjects with mild, moderate, and severe fibromyalgia, respectively.

CONCLUSIONS: Direct and indirect costs related to fibromyalgia are higher among subjects with worse fibromyalgia severity. Indirect costs account for a majority of fibromyalgia-related costs at all fibromyalgia severity levels.

J Manag Care Pharm. 2012;18(6):415-26

Copyright $\odot 2012$, Academy of Managed Care Pharmacy. All rights reserved.

\section{What is already known about this subject}

- Fibromyalgia is a chronic disorder characterized by persistent widespread pain, fatigue, and other symptoms; it is associated with a number of comorbid conditions and may lead to high rates of health care resource use (HRU). Retrospective analyses of administrative claims by Berger et al. (2007), White et al. (2008), and Robinson et al. (2003) estimated that patients with fibromyalgia average 12 to 18 physician office visits per year, with annual average all-cause direct medical costs of $\$ 4,393$ to $\$ 9,573$ per patient. However, these analyses were limited to all-cause costs, did not measure all patient out-of-pocket costs, and were not calculated by severity level.

- White et al. estimated that the mean cost of absenteeism related specifically to medical visits and employer disability claims for persons with fibromyalgia was $\$ 2,913$ in 2005 and accounted for $28.6 \%$ of combined direct and indirect costs. White et al. did not estimate the cost of other fibromyalgia-related lost productivity.

- Using the same sample as the present study, Schaefer et al. (2011) reported differences across fibromyalgia severity levels in selected categories of (a) fibromyalgia-related HRU, including physician office visits and proportion of subjects receiving medications, and (b) productivity loss, including absenteeism, presenteeism, changes in employment status, and unpaid informal care. Based on 3-month physician office reports, Schaefer et al. estimated that on average, study subjects with mild, moderate, and severe fibromyalgia visited physicians 9.7, 11.6, and 19.9 times per year, respectively. Patients also reported missing 0.4, 1.0, and 3.0 days 


\section{What is already known about this subject (continued)}

from work and receiving 3.6, 22.8, and 35.4 hours of unpaid informal care, such as child care, housework, yard work, or other daily activities that they could not perform due to fibromyalgia, over the past 4 weeks. However, the direct and indirect costs associated with these resources and productivity loss were not reported.

- A recent European study by Winkelmann et al. (2011) evaluated fibromyalgia-related costs using a methodology similar to that of the present study and found that more than three-quarters of total fibromyalgia-related costs in 2008 were attributable to lost productivity and disability, $88.5 \%$ in France and $75.7 \%$ in Germany, with the remainder attributable to direct costs.

\section{What this study adds}

- For a convenience sample of U.S. patients with fibromyalgia and a recent history of pain, the present study collected data from patients and physicians on HRU and costs attributable to different fibromyalgia severity levels as measured by the Fibromyalgia Impact Questionnaire. For patients with mild, moderate, and severe fibromyalgia, estimated mean 3-month direct HRU costs were $\$ 1,213, \$ 1,415$, and $\$ 2,329$, corresponding to annualized means of $\$ 4,854, \$ 5,662$, and $\$ 9,318$ per patient, respectively.

- The mean 4-week direct costs to subjects for medications and treatments to treat symptoms associated with fibromyalgia, as well as for professional services for help with daily activities, were higher among subjects with worse fibromyalgia severity (mild $\$ 120$, moderate $\$ 150$, and severe \$225).

- Indirect costs associated with subject-reported lost productivity and unpaid informal care attributable to fibromyalgia were found to be much higher in our study than previously reported for the United States: 3 -month means of $\$ 1,341, \$ 5,139$, and $\$ 8,285$, corresponding to annualized means of $\$ 5,366, \$ 20,556$, and $\$ 33,139$ per patient with mild, moderate, and severe fibromyalgia, respectively. Indirect costs accounted for $52.5 \%, 78.4 \%$, and $78.1 \%$ of total fibromyalgia-related costs for patients with mild, moderate, and severe fibromyalgia, respectively.

$\mathrm{F}$ ibromyalgia is the most common cause of widespread musculoskeletal pain and is estimated to affect $2 \%$ of the general U.S. population, based on the American College of Rheumatology criteria of widespread pain for at least 3 months and tenderness in 11 out of 18 tender points. ${ }^{1,2}$ Fibromyalgia patients are reported to be high consumers of health care services, due in part to the chronic nature of the condition, as well as the complexity of symptoms involved. ${ }^{3-6}$ Patients with fibromyalgia report pain, fatigue, sleep disturbance, and substantial limitations in physical function and independent activities of daily living (e.g., shopping, climbing stairs), ${ }^{7-10}$ which may lead to lost productivity in terms of higher absenteeism and presenteeism (attending work with compromised productivity), unemployment, and disability. ${ }^{10-13}$ Additionally, patients with fibromyalgia often require additional resources, such as unpaid assistance from family or paid caregivers, for help with independent activities of daily living. $4,7,10$

Several previous studies in the United States, including retrospective claims analyses and a prospective survey, have documented direct health care costs among patients with fibromyalgia. ${ }^{6,12-15}$ The claims analyses captured all-cause medical costs and, thus, may not have captured medical costs directly attributable to fibromyalgia. Also, while these studies captured patient out-of-pocket costs for medical services and prescription medications, they did not capture additional out-of-pocket costs incurred by patients, including costs for professional services to help perform daily activities hindered by fibromyalgia, such as child care, housework, or yard work. One prospective survey captured fibromyalgia-related treatment information directly from patients enrolled through rheumatologists' offices; however, results reflected resource use in the period 1988 to 1995 and 1996 costs. ${ }^{14}$ Two previous U.S. studies estimated indirect costs among patients with fibromyalgia due to absenteeism resulting from medical episodes of care, such as hospitalization or physician office visits, and the employer costs of disability claims. ${ }^{12,13}$ However, other lost productivity costs due to fibromyalgia-related absenteeism, presenteeism, unemployment, disability, and informal care were not explored in these studies.

A previously published article based on the sample used in the present study reported differences across fibromyalgia severity levels in selected categories of resource use, including (a) fibromyalgia-related physician office visits and proportion of subjects receiving medications for fibromyalgia and (b) productivity loss, including absenteeism, presenteeism, changes in employment status, and unpaid informal care. However, the direct and indirect costs associated with these resources and productivity loss were not calculated. ${ }^{10}$ Prior to the present study, no U.S. study had evaluated both direct and indirect health care costs due to fibromyalgia, by severity level, using patient-level data from both the medical chart and a patient survey. Additionally, no prior studies had comprehensively examined patient out-of-pocket costs reported by fibromyalgia patients in the United States. In contrast, 2 European studies found that indirect costs due to lost productivity and patient out-of-pocket expenses related to fibromyalgia are a substantial proportion of the total economic burden associated with the condition. ${ }^{4,16}$

Consequently, building on previous research, the objective of the present study was to assess comprehensively, by fibromyalgia severity level, health resource use (HRU) and direct and indirect costs associated with fibromyalgia in routine clinical practice in the United States. 


\section{Methods}

\section{Study Design}

This cross-sectional, observational study recruited a nonprobability convenience sample of patients with fibromyalgia between August 2008 and February 2009 from 20 U.S. community-based physician practices including 8 primary care physicians, 6 rheumatologists, 3 neurologists, and 3 psychiatrists. Previous research has shown that a majority of patients with fibromyalgia seek care from primary care and other physicians; less than $20 \%$ seek care from rheumatologists. ${ }^{12,17}$ These physician specialties were selected because they represent 4 specialties that treat fibromyalgia in the United States.

A study feasibility questionnaire was sent to 225 physicians treating fibromyalgia patients. Of 42 sites that returned surveys expressing interest in the study, 20 sites were selected following a pre-study visit, taking into account distribution across geographic region and physician specialties. There were 10 solo practices and 10 group practices with 1 primary investigator per site; however, multiple staff members were involved in collecting the data.

Participating physicians and trained site coordinators identified potential subjects as they presented for routine office visits. For inclusion in the study, subjects were required to (a) be aged 18 through 65 years; (b) have documentation in the medical chart of a prior diagnosis of fibromyalgia made by a rheumatologist, neurologist, or pain specialist; (c) have experienced widespread pain (above and below the waist and on both sides of the body) for at least 3 months and pain in the previous 24 hours; and (d) have received treatment at the participating physician's practice for at least 3 months.

Subjects were excluded if they had participated in an investigational drug study within 30 days prior to the study or had a concomitant illness unrelated to fibromyalgia that was likely to confound the assessment of fibromyalgia-related pain. Exclusion for concomitant illness was made at the discretion of the investigator based on guidance provided in the study protocol ("osteoarthritis or autoimmune musculoskeletal conditions such as rheumatoid arthritis, lupus, etc."). Subjects older than 65 years were excluded to estimate lost productivity among the working-age population. Counts of potential subjects screened for this study and of those removed from the sample for each exclusion criterion were not captured.

Participating physicians and trained site coordinators (e.g., nurse, physician assistant, clinical research coordinator, master's degree in science or business) obtained written informed consent from potential subjects for participation in the study, which included subject completion of the patient questionnaire and site staff completion of a paper case report form (CRF). Participating physicians were required to document on the CRF that subjects met the study inclusion and exclusion criteria and provided written informed consent.
Once consented, subjects were asked to complete a selfadministered patient questionnaire. Participating physicians performed an examination, using the Manual Tender Point Survey (MTPS) exam ${ }^{18}$ and completed the CRF based on a review of the subject's medical records. Information recorded on the CRF included the subject's clinical characteristics; physician's assessment of subjects' fibromyalgia severity; current and previous medications for fibromyalgia; and fibromyalgiarelated office visits, diagnostic tests, emergency room (ER) visits, and hospitalizations during the previous 3 months (i.e., the 3 months prior to data collection). Assessments of medications prescribed for fibromyalgia and of other fibromyalgiarelated HRU were based on physician judgment. Medications were not required to be U.S. Food and Drug Administration (FDA)-approved for fibromyalgia treatment because at the time of the study only 2 FDA-approved medications were available for the treatment of pain associated with fibromyalgia: pregabalin (Lyrica) and duloxetine (Cymbalta). Physicians were compensated $\$ 325$ per subject with a completed CRF and patient questionnaire. Subjects were compensated $\$ 50$ per completed patient questionnaire.

Information collected with the patient questionnaire and CRF was not associated with the subject's personal identifying information but was associated with a study-specific identifier assigned at enrollment to allow linking of individual subject's CRF and questionnaire data in the analysis. The study protocol was approved by Schulman Associates Institutional Review Board, Inc. (Cincinnati, Ohio). All subjects provided written informed consent.

\section{Patient Questionnaire and Assessment of Fibromyalgia Severity}

The 106-item patient questionnaire included 5 validated health-related quality-of-life instruments: the EuroQol (EQ5D), ${ }^{19}$ the Fibromyalgia Impact Questionnaire (FIQ), ${ }^{20}$ the Multidimensional Assessment of Fatigue (MAF), ${ }^{21}$ the Medical Outcomes Study (MOS) Sleep Scale, ${ }^{22}$ and the Hospital Anxiety and Depression Scale (HADS). ${ }^{23}$ Subject-specific pain associated with fibromyalgia over the previous 24 hours was assessed by a 1-item average pain question with an 11-point numeric rating scale. In addition, study-specific questions were developed to assess demographics and clinical history ( $n=4$ items), overall health and impact of fibromyalgia on cognitive function and daily activities ( $\mathrm{n}=13$ items), treatment satisfaction ( $n=2$ items), out-of-pocket expenses related to fibromyalgia ( $n=9$ items), and impact of fibromyalgia on employment status and productivity ( $n=9$ items). Subjects also reported hours of unpaid informal care for daily activities, such as child care, housework, or yard work, that they could not perform due to fibromyalgia; out-of-pocket expenses for medical and nonmedical services; and lost productivity for the previous 4 weeks. Subject reports of direct out-of-pocket costs for HRU, direct 
nonmedical costs for paid assistance with daily activities, lost work hours, and informal care could not be verified.

The FIQ is a 20 -item assessment that generates 10 subscales measuring fibromyalgia patient status in the areas of physical impairment, feeling good, work missed, doing work, pain, fatigue/tired, rested, stiffness, anxiety, and depression. ${ }^{20,24}$ Each of the subscales has a maximum possible score of 10 . The FIQ total score (range: 0 to 100) is the sum of the 10 FIQ subscale scores, with higher scores indicating worse severity. Subjects' FIQ total scores were used to define fibromyalgia severity as follows: 0 to less than $39=$ mild, 39 to less than $59=$ moderate, and 59 to $100=$ severe..$^{25}$

\section{Cost Estimates}

Direct and indirect costs associated with fibromyalgia were estimated in 2009 U.S. dollars from a societal perspective. Costs included direct medical costs (diagnostic tests, physician office visits, prescription medications, hospitalizations, ER visits, and patient out-of-pocket costs for HRU related to fibromyalgia); direct nonmedical costs (patient out-of-pocket costs for assistance with daily activities); and indirect costs (lost productivity and informal care due to fibromyalgia). All costs were estimated because no cost data were available.

As a proxy for direct medical cost, unit costs based on fiscal year (FY) 2009 Medicare payment rates were assigned to the 3-month HRU data recorded by physicians on the CRF. Unit costs for office visits and office-based procedures or tests were assigned based on the FY 2009 Medicare Physician Fee Schedule (MPFS) ${ }^{26}$ Unit costs for ER visits not resulting in hospital admission were assigned based on the FY 2009 Medicare Hospital Outpatient Prospective Payment System (OPPS). ${ }^{27}$ Unit costs for medications prescribed to treat symptoms associated with fibromyalgia were assigned based on $80 \%$ of average wholesale price (AWP) ${ }^{28}$ taken from the 2009 ReadyPrice (Thomson Reuters, New York, NY) ${ }^{29}$ Four-week out-of-pocket costs for HRU related to fibromyalgia, as well as for assistance with daily activities, were directly reported by subjects.

An estimate of total annualized direct medical costs was then calculated by summing (a) the estimated 3-month HRU costs multiplied by 4 , plus (b) the subject-reported 4-week outof-pocket costs for HRU multiplied by 13. Annualized direct nonmedical costs were estimated by multiplying the subjectreported 4-week out-of-pocket costs for assistance with daily activities by 13. The 3-month estimate for the subject-reported 4 -week out-of-pocket costs was calculated by dividing the total annualized cost by 4 .

For indirect costs, unit costs were assigned to subject and informal care (caregiver) lost productivity based on average wage data from the National Bureau of Labor Statistics. ${ }^{30}$ For subjects employed full or part time, the average wage rate of $\$ 19.88$ per hour was assigned to (a) subject-reported days missed from work over the previous 4 weeks due to fibromy- algia and (b) hours of work time lost from reduced work hours due to fibromyalgia. For subjects who were unemployed or disabled due to fibromyalgia, the average wage rate was applied to days of work time lost from the subject-reported date of unemployment or disability due to fibromyalgia, for a maximum of 3 months. In addition, the average monthly disability payment of $\$ 1,004$ was included for the number of months the subject reported disability due to fibromyalgia, for a maximum of 3 months. ${ }^{31}$

To estimate the monetary value of informal care time, the average wage rate of $\$ 19.88$ was applied to the number of hours that subjects reported they received unpaid informal care for daily activities over the previous 4 weeks. An estimate of annualized indirect costs was calculated by summing (a) the subject-reported disability, unemployment, or reduced work schedule costs multiplied by 4 , plus (b) the subject-reported 4-week unpaid informal care and absenteeism costs multiplied by 13. Additionally, the 3-month costs for the subject-reported 4-week absenteeism and unpaid informal care were calculated by dividing the total annualized cost by 4 .

\section{Statistical Analysis}

Summary statistics were calculated including means, standard deviations (SD), medians, and ranges for continuous variables and frequency distributions for categorical variables. Differences in direct and indirect costs and continuous measures of HRU were compared across fibromyalgia severity levels using the Kruskal-Wallis test. Categorical outcomes were compared across fibromyalgia severity levels using the Pearson chi-square test or the Fisher's exact test.

Statistical significance was evaluated at the 0.05 alpha level. All analyses were performed using PC-SAS version 9.1 (SAS Institute, Cary, North Carolina).

\section{Results}

\section{Demographic and Clinical Characteristics}

Table 1 summarizes the demographic and clinical characteristics of this sample, which have been previously published. ${ }^{10}$ The study enrolled a total of 203 subjects with fibromyalgia. At the time of the study, subjects reported a mean (SD) FIQ total score of 63.2 (19.0) out of 100. Based on FIQ scores, 21 (10.3\%), 49 (24.1\%), and 133 (65.5\%) subjects were classified as having mild, moderate, and severe fibromyalgia, respectively. There were no significant differences in the subjects' age, gender, time since first experiencing fibromyalgia symptoms, time since diagnosis, or time since first prescription for fibromyalgia across the fibromyalgia severity levels (Table 1).

There were significant differences in employment status across severity levels $(P<0.001$; Table 1$)$. Among subjects with mild fibromyalgia, $61.9 \%(n=13)$ were employed full time, and none reported being disabled. In contrast, $19.5 \%(n=26)$ of subjects with severe fibromyalgia were employed full time, and 
The Comparative Economic Burden of Mild, Moderate, and Severe Fibromyalgia:

Results from a Retrospective Chart Review and Cross-Sectional Survey of Working-Age U.S. Adults

TABLE 1 Demographic and Clinical Characteristics of Study Subjects by Fibromyalgia Severity Level ${ }^{a}$

\begin{tabular}{|c|c|c|c|c|c|c|c|}
\hline \multirow[b]{2}{*}{ Characteristic } & \multicolumn{7}{|c|}{ Fibromyalgia Severity Level $(\mathrm{N}=203)^{\mathrm{b}}$} \\
\hline & \multicolumn{2}{|c|}{ Mild $(n=21)$} & \multicolumn{2}{|c|}{ Moderate $(n=49)$} & \multicolumn{2}{|c|}{ Severe $(n=133)$} & \multirow{2}{*}{$\begin{array}{c}\text { Value }^{\mathrm{c}} \\
0.148\end{array}$} \\
\hline Age, years & & & & & & & \\
\hline Mean [SD] & 48.6 & [11.9] & 45.3 & [11.0] & 48.7 & {$[10.6]$} & \\
\hline Median (range) & 53.0 & $(28.0-65.0)$ & 46.0 & $(19.0-64.0)$ & 50.0 & $(21.0-65.0)$ & \\
\hline Gender, \% (n) female & 90.5 & (19) & 93.9 & $(46)$ & 95.5 & $(127)$ & 0.621 \\
\hline Employment status, \% (n)d & & & & & & & $<0.001$ \\
\hline Employed, full time & 61.9 & (13) & 36.7 & (18) & 19.5 & (26) & \\
\hline Employed, part time & 9.5 & $(2)$ & 24.5 & $(12)$ & 9.0 & $(12)$ & \\
\hline Disabled & 0.0 & $(0)$ & 14.3 & $(7)$ & 36.1 & $(48)$ & \\
\hline Full-time homemaker & 19.0 & (4) & 10.2 & (5) & 12.0 & (16) & \\
\hline Unemployed & 4.8 & $(1)$ & 2.0 & $(1)$ & 10.5 & $(14)$ & \\
\hline Retired & 4.8 & $(1)$ & 6.1 & (3) & 6.0 & $(8)$ & \\
\hline Other & 0.0 & $(0)$ & 4.1 & $(2)$ & 4.5 & $(6)$ & \\
\hline Student & 0.0 & $(0)$ & 2.0 & $(1)$ & 2.3 & (3) & \\
\hline Time since first experienced fibromyalgia symptoms, years ${ }^{\mathrm{e}}$ & & & & & & & 0.684 \\
\hline Mean [SD] & 10.8 & {$[6.3]$} & 10.1 & {$[8.1]$} & 10.9 & {$[8.3]$} & \\
\hline Median (range) & 10.0 & $(3.0-23.0)$ & 9.0 & $(1.0-32.0)$ & 9.0 & $(0.0-48.0)$ & \\
\hline Time since diagnosis, years ${ }^{f}$ & & & & & & & 0.604 \\
\hline Mean [SD] & 7.4 & {$[6.1]$} & 6.2 & {$[6.2]$} & 7.0 & {$[6.6]$} & \\
\hline Median (range) & 6.0 & $(0.0-22.0)$ & 4.0 & $(0.0-30.0)$ & 6.0 & $(0.0-48.0)$ & \\
\hline Time since first prescription for fibromyalgia, years ${ }^{\mathrm{e}}$ & & & & & & & 0.670 \\
\hline Mean $[S D]$ & 7.2 & {$[6.6]$} & 5.9 & {$[6.6]$} & 6.2 & {$[6.0]$} & \\
\hline Median (range) & 5.0 & $(0.0-22.0)$ & 3.0 & $(0.0-30.0)$ & 5.0 & $(0.0-21.0)$ & \\
\hline \multicolumn{8}{|l|}{ Comorbid conditions, $\%(n)^{\mathrm{f}, \mathrm{g}}$} \\
\hline Sleep disturbance/insomnia & 52.4 & $(11)$ & 71.4 & $(35)$ & 69.2 & $(92)$ & 0.259 \\
\hline Depressive symptoms & 23.8 & $(5)$ & 40.8 & $(20)$ & 69.2 & $(92)$ & $<0.001$ \\
\hline Headache/migraine & 47.6 & $(10)$ & 53.1 & $(26)$ & 51.9 & $(69)$ & 0.915 \\
\hline Anxiety & 19.0 & (4) & 40.8 & $(20)$ & 57.9 & $(77)$ & 0.002 \\
\hline Chronic fatigue syndrome & 9.5 & (2) & 53.1 & (26) & 43.6 & $(58)$ & 0.003 \\
\hline Irritable bowel syndrome & 23.8 & $(5)$ & 34.7 & $(17)$ & 39.1 & $(52)$ & 0.384 \\
\hline Restless leg syndrome & 14.3 & (3) & 32.7 & $(16)$ & 29.3 & $(39)$ & 0.281 \\
\hline Cognitive dysfunction & 9.5 & (2) & 30.6 & (15) & 28.6 & (38) & 0.154 \\
\hline Major depressive disorder & 0.0 & $(0)$ & 22.4 & $(11)$ & 27.1 & $(36)$ & 0.024 \\
\hline Raynaud's syndrome & 9.5 & $(2)$ & 10.2 & $(5)$ & 6.0 & $(8)$ & 0.584 \\
\hline Number of comorbid conditions $s^{\mathrm{f}, \mathrm{h}}$ & & & & & & & 0.112 \\
\hline Mean [SD] & 2.9 & {$[1.6]$} & 4.1 & {$[2.3]$} & 4.4 & {$[2.6]$} & \\
\hline Median (range) & 3.0 & $(1.0-7.0)$ & 4.0 & $(1.0-10.0)$ & 4.0 & $(1.0-10.0)$ & \\
\hline Number of positive MTPS points ${ }^{f}$ & & & & & & & 0.036 \\
\hline Mean [SD] & 13.7 & {$[4.1]$} & 13.8 & {$[3.8]$} & 15.2 & {$[3.0]$} & \\
\hline Median (range) & 16.0 & $(5.0-18.0)$ & 15.0 & $(4.0-18.0)$ & 16.0 & $(4.0-18.0)$ & \\
\hline \multicolumn{8}{|c|}{$\begin{array}{l}\text { aResults were previously published by Schaefer et al. (2011). }{ }^{10} \text { Noncopyrighted material. Source: BioMed Central (London, United Kingdom; http://www.biomedcentral. } \\
\text { bSeverity-level classification was based on Fibromyalgia Impact Questionnaire score: } 0 \text { to less than } 39=\text { mild; } 39 \text { to less than } 59=\text { moderate; } 59 \text { to } 100=\text { severe. } \\
\text { 'From the Pearson chi-square test, Fisher's exact test, or Kruskal-Wallis test, as appropriate. } \\
{ }^{d} \text { The P value is < } 0.001 \text { for both the Pearson chi-square test (using all employment status groupings) and the Fisher's exact test (using the collapsed groupings of emple } \\
\text { full or part time, disabled, homemaker, other). } \\
\text { 'Based on responses from the patient questionnaire. } \\
\text { fBased on responses from the site clinical case report form. } \\
\text { gSubjects may have more than } 1 \text { condition; thus, percentages may sum to more than 100\%. }\end{array}$} \\
\hline
\end{tabular}

36.1\% ( $\mathrm{n}=48)$ reported being disabled. Among subjects with moderate fibromyalgia, $36.7 \%(n=18)$ were employed full time $(n=18)$, and $14.3 \%(n=7)$ reported being disabled $(n=7)$. Of subjects with mild, moderate, and severe fibromyalgia, respectively, $71.4 \%, 61.2 \%$, and $28.6 \%$ reported being employed full time or part time.
Sleep disturbance/insomnia was the most common comorbid condition reported on the CRF across fibromyalgia severity levels, among $52.4 \%, 71.4 \%$, and $69.2 \%$ of mild, moderate, and severe fibromyalgia subjects, respectively (Table 1). Although there was a trend of an increasing mean number of comorbid conditions among subjects with worse fibromyalgia severity, 
The Comparative Economic Burden of Mild, Moderate, and Severe Fibromyalgia:

Results from a Retrospective Chart Review and Cross-Sectional Survey of Working-Age U.S. Adults

TABLE 2 Counts of Physician-Reported

Fibromyalgia-Related Medications,

Emergency Room Visits, and Office Visits, by Fibromyalgia Severity Level ${ }^{\mathrm{a}}$

\begin{tabular}{|c|c|c|c|c|}
\hline \multirow[b]{2}{*}{ Service Type } & \multicolumn{4}{|c|}{ Fibromyalgia Severity Level $(\mathrm{N}=203)$} \\
\hline & $\begin{array}{c}\mathrm{Mi} \\
(\mathrm{n}=\end{array}$ & (n & $\begin{array}{l}\mathrm{Se} \\
(\mathrm{n}=\end{array}$ & $\begin{array}{c}P \\
\text { Value }^{b}\end{array}$ \\
\hline Medications & & & & \\
\hline 3-month & 1.8 & 2.3 & 2.8 & \\
\hline $3-m$ & & & & \\
\hline ER vi & & & & 0 . \\
\hline $3-m$ & 0.0[ & 0.1 & 0.1 & \\
\hline 3-1 & (c) & 0.0 & 0) & \\
\hline Office & & & & $<0.001$ \\
\hline $3-n$ & 2 & & & \\
\hline 3-month median (range) & $1.0(1.0-12.0)$ & $3.0(1.0-28.0)$ & $4.0(1.0-57.0)$ & \\
\hline \multicolumn{5}{|c|}{$\begin{array}{l}{ }^{a} \text { Represents utilization attributable to fibromyalgia during the } 3 \text {-month period } \\
\text { prior to the record review as determined by subject's physician and recorded } \\
\text { on the site clinical case report forms. Severity-level classification was based on } \\
\text { Fibromyalgia Impact Questionnaire score: } 0 \text { to less than } 39=\text { mild; } 39 \text { to less than } \\
59=\text { moderate; } 59 \text { to } 100=\text { severe. }\end{array}$} \\
\hline \multicolumn{5}{|c|}{$\begin{array}{l}\text { In the moderate fibromyalgia group, there were } 4 \text { subjects with } 1 \text { ER visit; in the } \\
\text { severe fibromyalgia group, there were } 5 \text { subjects with } 1 \text { ER visit, } 1 \text { with } 2 \text { ER visits, } \\
\text { and } 1 \text { with } 3 \text { ER visits. }\end{array}$} \\
\hline \multicolumn{5}{|c|}{ 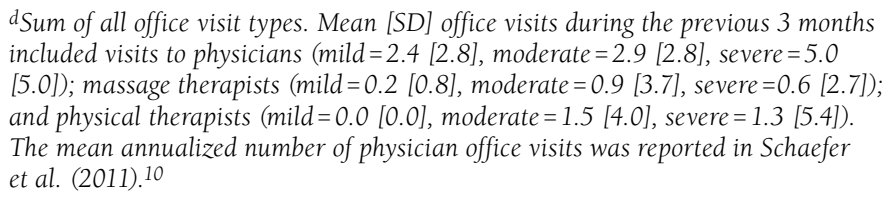 } \\
\hline & the & & & \\
\hline
\end{tabular}

the trend was not significant $(P=0.112)$. However, the proportion of subjects with certain comorbid conditions significantly increased as the severity level worsened: depressive symptoms $(P<0.001)$, anxiety $(P=0.002)$, and major depressive disorder $(P=0.024)$. The number of positive MTPS points reported by physicians on the CRF following the MTPS exams also was significantly different across severity levels, with a mean (SD) positive tender points of 13.7 (4.1) in mild, 13.8 (3.8) in moderate, and $15.2(3.0)$ in severe fibromyalgia $(P=0.036)$.

\section{Medical Resource Use}

The mean (SD) reported number of medications prescribed to treat the symptoms of fibromyalgia during the 3 previous months (i.e., the 3 months prior to data collection) was higher among subjects with worse fibromyalgia severity: 1.8 (1.0), 2.3 (1.5), and 2.8 (1.6) for patients with mild, moderate, and severe fibromyalgia, respectively $(P=0.011$; Table 2$)$. Antidepressants, opioids, and antiepileptics were the most commonly prescribed medications across fibromyalgia severity levels (Figure 1). During the 3 previous months, antidepres-
TABLE 3 Subject-Reported Impact of Fibromyalgia on Employment Status by Fibromyalgia Severity Level ${ }^{a}$

\begin{tabular}{|c|c|c|c|c|}
\hline \multirow[b]{2}{*}{ Impact of Fibromyalgia } & \multicolumn{4}{|c|}{ Fibromyalgia Severity Level } \\
\hline & Mild & Moderate & Severe & $P$ Value $^{\mathrm{b}}$ \\
\hline $\begin{array}{l}\text { Impact of fibromyalgia on } \\
\text { employment status among } \\
\text { subjects employed for pay full } \\
\text { or part time }(n=83), \%(n)\end{array}$ & & & & 0.039 \\
\hline None & $100.0(15)$ & $66.7(20)$ & $78.4(29)$ & \\
\hline $\begin{array}{l}\text { Reduction of scheduled } \\
\text { work time }\end{array}$ & $0.0 \quad(0)$ & $33.3(10)$ & $21.6 \quad(8)$ & \\
\hline $\begin{array}{l}\text { Days missed from work due to } \\
\text { fibromyalgia during the previ- } \\
\text { ous } 4 \text { weeks among subjects } \\
\text { employed for pay full or part } \\
\text { time (n=83), \% (n) }\end{array}$ & & & & 0.011 \\
\hline 0 days & 85.7 (12) & $58.6(17)$ & 45.7 (16) & \\
\hline $1-5$ days & $14.3 \quad(2)$ & $41.4(12)$ & $34.3(12)$ & \\
\hline More than 5 days & $0.0 \quad(0)$ & $0.0 \quad(0)$ & $20.0 \quad(7)$ & \\
\hline $\begin{array}{l}\text { Impact of fibromyalgia on } \\
\text { employment status among } \\
\text { subjects not employed for pay } \\
(\mathrm{n}=120), \%(\mathrm{n})\end{array}$ & & & & 0.145 \\
\hline None & $66.7 \quad(4)$ & $35.7 \quad(5)$ & $24.4(21)$ & \\
\hline Disabled & $0.0 \quad(0)$ & $28.6 \quad(4)$ & $41.9(36)$ & \\
\hline Unemployed or retired early & $33.3 \quad(2)$ & $35.7 \quad(5)$ & $33.7(29)$ & \\
\hline \multicolumn{5}{|c|}{$\begin{array}{l}\text { aReported by patients based on responses to questions about the impact of } \\
\text { fibromyalgia on employment status. Severity-level classification was based on } \\
\text { Fibromyalgia Impact Questionnaire score: } 0 \text { to less than } 39=\text { mild; } 39 \text { to less than } \\
59=\text { moderate; } 59 \text { to } 100=\text { severe. } \\
\text { bFrom the Pearson chi-square test. Using a Bonferroni-adjusted critical P value } \\
\text { of } 0.017 \text { ( } n=3 \text { comparisons) for the analyses presented in Table 3, between-group } \\
\text { differences would no longer be significant for employment status among subjects } \\
\text { employed for pay full or part time. }\end{array}$} \\
\hline
\end{tabular}

sants were prescribed for $47.6 \%, 55.1 \%$, and $57.9 \%$; opioids for $38.1 \%, 44.9 \%$, and $48.1 \%$; and antiepileptics for $19.0 \%, 26.5 \%$, and $42.9 \%$ of subjects with mild, moderate, and severe fibromyalgia, respectively.

Visits to physicians and other health care professionals were more frequent among subjects with worse fibromyalgia severity (Table 2). In addition to the physician visits, $9.5 \%, 26.5 \%$, and $21.1 \%$ of mild, moderate, and severe fibromyalgia subjects also had at least one visit to a physical or massage therapist (data not shown in table). For subjects with mild, moderate, and severe fibromyalgia, respectively, mean (SD) total office visit counts, which include visits to physicians and physical and massage therapists, were 2.7 (3.3), 5.2 (7.1), and 6.9 (8.9) during the previous 3 months, corresponding to annualized mean (SD) counts of 10.7 (13.0), 20.9 (28.4), and 27.7 (35.6; annualized data not shown in table).

Visits to the ER were rare: during the 3-month reporting period, there were no ER visits observed among subjects with mild fibromyalgia; 4 ER visits were observed among 4 
The Comparative Economic Burden of Mild, Moderate, and Severe Fibromyalgia:

Results from a Retrospective Chart Review and Cross-Sectional Survey of Working-Age U.S. Adults

\section{FIGURE 1 Percentages of Study Subjects on Medication During the Previous}

3 Months by Drug Therapy Class and Fibromyalgia Severity Level ${ }^{a}$

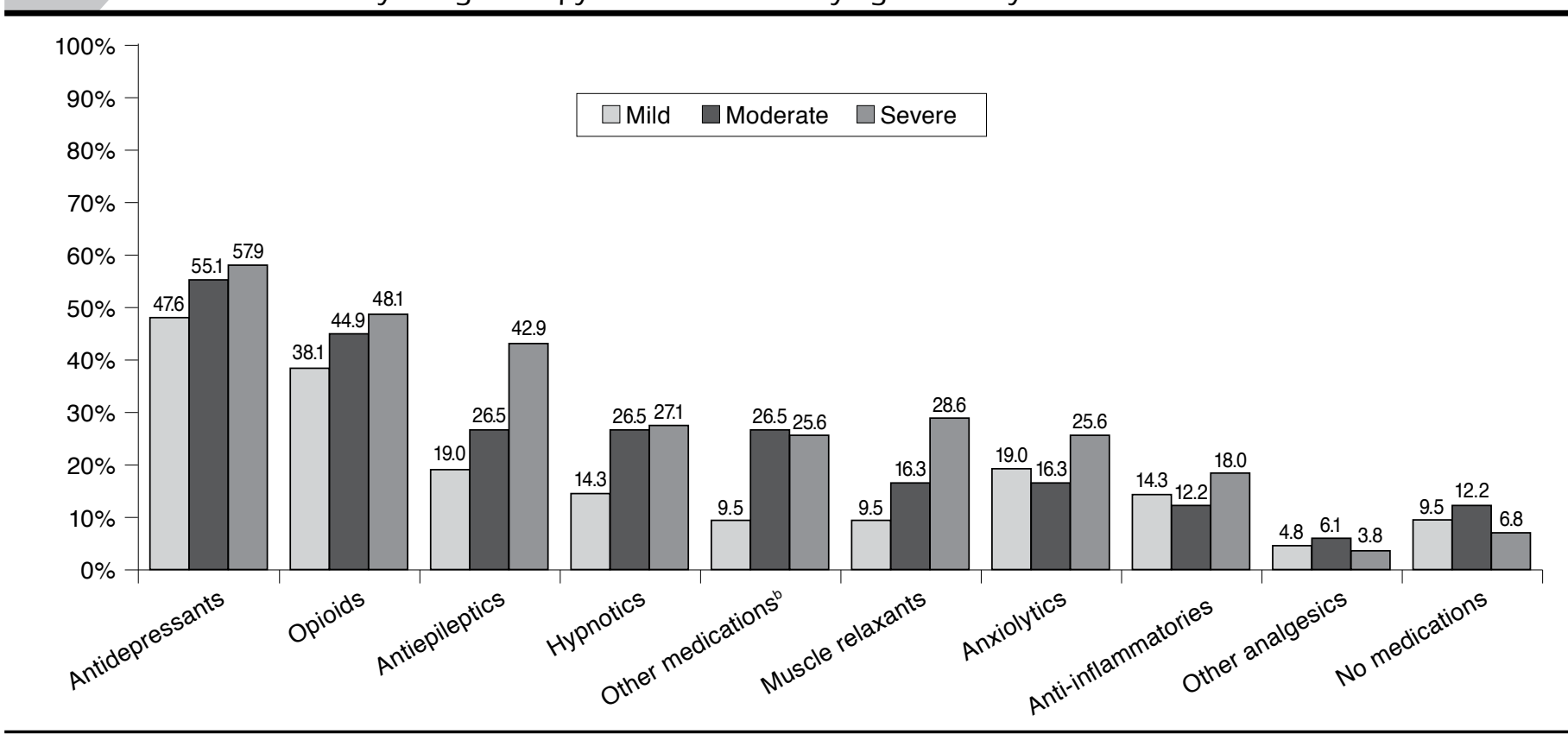

aRepresents medications prescribed to subject for fibromyalgia during the 3-month period prior to the record review as determined by subject's physician and recorded on the site clinical case report forms. Severity-level classification was based on Fibromyalgia Impact Questionnaire score: 0 to less than $39=$ mild; 39 to less than $59=$ moderate 59 to $100=$ severe.

${ }^{b}$ Other medications include prescription medications such as lidocaine, diclofenac epolamine, quetiapine fumarate, pramipexole dihydrochloride, and zolpidem tartrate.

subjects with moderate fibromyalgia (mean $=0.1$ ); and $10 \mathrm{ER}$ visits were observed among 7 subjects with severe fibromyalgia (mean $=0.1$ ).

\section{Employment and Lost Productivity}

Among employed subjects, there were significant differences across severity levels in the number of days missed from work during the previous 4 weeks $(P=0.011$; Table 3$)$. For example, $14.3 \%$ of subjects with mild fibromyalgia missed some work during the previous 4 weeks compared with $54.3 \%$ of subjects with severe fibromyalgia. Similarly, no subjects with mild fibromyalgia missed more than 5 days of work during the previous 4 weeks compared with $20.0 \%$ of subjects with severe fibromyalgia.

Among subjects who were not employed, substantial proportions in all severity categories reported some impact of fibromyalgia on their employment status; however, the impact of fibromyalgia on disability/unemployment status was not significantly different across severity levels. No subjects ( $0.0 \%)$, $28.6 \%$, and $41.9 \%$ of those with mild, moderate, and severe fibromyalgia, respectively, reported being disabled; and 33.3\%, $35.7 \%$, and $33.7 \%$, respectively, reported being unemployed or retired early due to fibromyalgia $(P=0.145)$.

\section{Out-of-Pocket Costs}

Total subject-reported direct medical and nonmedical out-ofpocket costs were higher among subjects with worse fibromyalgia severity (Table 4). The 4-week mean (median) out-of-pocket costs for subjects with mild, moderate, and severe fibromyalgia were $\$ 120$ (\$43), $\$ 150$ (\$80), and $\$ 225$ (\$111), respectively (3-month costs shown in Table 4; $P=0.025)$. For subjects with mild, moderate, and severe fibromyalgia, respectively, these 4-week out-of-pocket costs comprised means (medians) of $\$ 21$ (\$10), \$59 (\$40), and $\$ 78$ (\$36) for prescription medications; $\$ 4(\$ 0), \$ 13(\$ 10)$, and $\$ 21$ (\$5) for nonprescription medications; $\$ 26(\$ 0), \$ 37(\$ 0)$, and $\$ 29(\$ 0)$ for physical treatments; $\$ 11(\$ 0), \$ 16(\$ 0)$, and $\$ 27(\$ 0)$ for herbs, vitamins, and other supplements for fibromyalgia; and $\$ 58(\$ 0), \$ 24(\$ 0)$, and $\$ 70$ $(\$ 0)$ for professional services to assist with daily activities that subjects reported being unable to perform due to fibromyalgia (data not shown). The 4-week total out-of-pocket costs correspond to 3-month mean (median) total out-of-pocket costs of $\$ 390$ (\$140), \$487 (\$260), and \$731 (\$361) for subjects with mild, moderate, and severe fibromyalgia, respectively.

\section{Total 3-Month and Annualized Costs}

Total costs include (a) direct medical costs incurred by payers and out-of-pocket costs paid by subjects for HRU that include 
The Comparative Economic Burden of Mild, Moderate, and Severe Fibromyalgia:

Results from a Retrospective Chart Review and Cross-Sectional Survey of Working-Age U.S. Adults

TABLE 4 Total 3-Month and Annualized Costs (\$) Per Study Subject by Fibromyalgia Severity Level ${ }^{a}$

Fibromyalgia Severity Level $(\mathrm{N}=203)$

Type of Cost

\begin{tabular}{|c|c|c|c|c|c|c}
\hline \multicolumn{2}{|c|}{ Mild $(\mathrm{n}=21)$} & \multicolumn{2}{|c|}{ Moderate $(\mathrm{n}=49)$} & \multicolumn{2}{c|}{ Severe $(\mathrm{n}=133)$} & $P$ \\
\cline { 1 - 5 } Mean [SD] & Median (Range) & Mean [SD] & Median (Range) & Mean [SD] & Median (Range) & Value $^{\mathrm{b}}$ \\
\hline
\end{tabular}

Three-month costs

Direct medical costs to payer for fibromyalgia-related HRUc

\begin{tabular}{|c|c|c|c|c|c|c|c|c|c|c|c|c|c|}
\hline Physician visits & 173 & [209] & 66 & $(66-786)$ & 322 & {$[418]$} & 177 & $(66-1,668)$ & 437 & [532] & 265 & $(66-3,514)$ & $<0.001$ \\
\hline Diagnostic tests & 31 & [98] & 0 & $(0-449)$ & 17 & [93] & 0 & $(0-649)$ & 155 & [565] & 0 & $(0-3,965)$ & 0.050 \\
\hline Prescription medications & 620 & [702] & 385 & $(0-2,329)$ & 577 & [473] & 574 & $(0-1,863)$ & 994 & {$[1,036]$} & 687 & $(0-4,876)^{d}$ & 0.071 \\
\hline ER visits & 0 & [0] & 0 & $(0-0)$ & 13 & [44] & 0 & $(0-191)$ & 12 & [63] & 0 & $(0-574)$ & 0.381 \\
\hline Hospitalizations & 0 & {$[0]$} & 0 & $(0-0)$ & 0 & {$[0]$} & 0 & $(0-0)$ & 0 & [0] & 0 & $(0-0)$ & NA \\
\hline $\begin{array}{l}\text { Direct costs to subject-out-of- } \\
\text { pocket costs for fibromyalgiae }\end{array}$ & 390 & {$[637]$} & 140 & $(0-2,155)$ & 487 & [644] & 260 & $(0-2,665)$ & 731 & {$[1,222]$} & 361 & $(0-12,025)$ & 0.025 \\
\hline $\begin{array}{l}\text { Direct out-of-pocket } \\
\text { medical costs }\end{array}$ & 202 & {$[332]$} & 124 & $(0-1,479)$ & 407 & [532] & 244 & $(0-2,438)$ & 504 & [872] & 260 & $(0-8,775)$ & 0.031 \\
\hline $\begin{array}{l}\text { Direct out-of-pocket } \\
\text { nonmedical costs }\end{array}$ & 188 & [410] & 0 & $(0-1,560)$ & 79 & [276] & 0 & $(0-1,625)$ & 227 & [486] & 0 & $(0-3,250)$ & 0.052 \\
\hline $\begin{array}{l}\text { Total direct costs due } \\
\text { to fibromyalgia }\end{array}$ & 1,213 & [877] & 1,150 & $(66-3,072)$ & 1,415 & {$[1,040]$} & 1,215 & $(98-4,650)$ & 2,329 & {$[2,076]$} & 1,760 & $(66-14,276)$ & 0.002 \\
\hline
\end{tabular}

Indirect costs due to fibromyalgia (subject-reported) ${ }^{\mathrm{f}}$

\begin{tabular}{|c|c|c|c|c|c|c|c|c|c|c|c|c|c|}
\hline Absenteeism ${ }^{\mathrm{g}}$ & 123 & [397] & 0 & $(0-1,551)$ & 240 & [504] & 0 & $(0-2,068)$ & 361 & {$[1,475]$} & 0 & $(0-14,473)$ & 0.248 \\
\hline Disability & 0 & [0] & 0 & $(0-0)$ & 1,090 & {$[3,693]$} & 0 & $(0-13,350)$ & 3,212 & {$[5,728]$} & 0 & $(0-13,350)$ & 0.004 \\
\hline Disability payments & 0 & [0] & 0 & $(0-0)$ & 246 & [833] & 0 & $(0-3,012)$ & 725 & {$[1,292]$} & 0 & $(0-3,012)$ & 0.004 \\
\hline $\begin{array}{l}\text { Lost productivity due } \\
\text { to disability }\end{array}$ & 0 & [0] & 0 & $(0-0)$ & 844 & {$[2,860]$} & 0 & $(0-10,337)$ & 2,487 & {$[4,436]$} & 0 & $(0-10,338)$ & 0.004 \\
\hline $\begin{array}{l}\text { Unemployment/early retire- } \\
\text { ment due to fibromyalgia }\end{array}$ & 985 & {$[3,109]$} & 0 & $(0-10,338)$ & 1,055 & {$[3,162]$} & 0 & $(0-10$ & 2,150 & {$[4,169]$} & 0 & $(0-$ & 0.120 \\
\hline $\begin{array}{l}\text { Reduced work schedule due to } \\
\text { fibromyalgia }\end{array}$ & 0 & [0] & 0 & $(0-0)$ & 1,282 & {$[2,790]$} & v & $(0-9,045)$ & 276 & {$[1,186]$} & 0 & 203) & 0.001 \\
\hline $\begin{array}{l}\text { Unpaid informal care due to } \\
\text { fibromyalgiah }\end{array}$ & 234 & [454] & 0 & $(0-1,938)$ & 1,473 & {$[6,478]$} & 0 & $(0-45,227)$ & 2,286 & {$[5,838]$} & 517 & ,519) & 0.003 \\
\hline $\begin{array}{l}\text { Total indirect costs } \\
\text { due to fibromyalgia }\end{array}$ & 1,341 & {$[3,362]$} & 0 & $(0-12,276)$ & 5,139 & {$[7,876]$} & 1,680 & $(0-46,778)$ & 8,285 & {$[9,142]$} & 7,030 & $(0-59,869)$ & $<0.001$ \\
\hline Total direct and indirect costs & 2,555 & {$[3,375]$} & 1,759 & $(287-12,777)$ & 6,554 & {$[8,221]$} & 3,614 & $(111-50,591)$ & 10,614 & {$[9,786]$} & 9,935 & $(66-61,774)$ & $<0.001$ \\
\hline \multicolumn{14}{|l|}{ Annualized costs ${ }^{i}$} \\
\hline Total direct costs & 4,854 & {$[3,509]$} & 4,600 & $262-12,288)$ & 5,662 & {$[4,159]$} & 4,861 & $(392-18,601)$ & 9,318 & {$[8,304]$} & 7,040 & $(262-57,102)$ & 0.002 \\
\hline Total indirect costs & $5,366[$ & $13,449]$ & 0 & $(0-49,104)$ & 20,556 & {$[31,505]$} & 6,719 & $(0-187,111)$ & 33,139 & {$[36,570]$} & 28,118 & $(0-239,475)$ & $<0.001$ \\
\hline tal direct and indirect costs & 10,219 & [1. & 7, & $147-51,110)$ & + & & 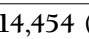 & + & 42,456 & {$[39,146]$} & 740 & 7,0 & $<0.001$ \\
\hline
\end{tabular}

a Severity-level classification was based on Fibromyalgia Impact Questionnaire score: 0 to less than $39=$ mild; 39 to less than $59=$ moderate; 59 to $100=$ severe.

${ }^{b}$ From the Kruskal-Wallis test. Using a Bonferroni-adjusted critical P value of 0.003 ( $n=18$ comparisons of 3-month costs), between-group differences in the following costs would no longer be significant: out-of-pocket costs to the subject (medical, nonmedical, and total); patient-reported disability costs (disability payments, lost productivity due to disability, and total); and unpaid informal care.

${ }^{c}$ Costs were estimated by applying 2009 Medicare fee schedule values to utilization attributable to fibromyalgia during the 3-month period prior to the record review as determined by subject's physician and recorded on the site clinical case report forms. Assumed costs per visit: physician visit $\$ 66.03$, massage therapist and physical therapist \$55.70, ER \$149.91. Sources included the Medicare fiscal year 2009 MPFS26 and hospital OPPS. 27

dMaximum of $\$ 4,876$ represents a study subject who used brand-name fluoxetine, clonazepam, celecoxib, modafinil, lidocaine, and tramadol hydrochloride continuously for the 3-month measurement period.

'Based on subject-reported data; 3-month costs were extrapolated from 4-week costs by multiplying 13 times the 4-week costs to calculate an annualized cost and then dividing by 4. Mean (median) 4-week out-of-pocket costs were $\$ 120$ (\$196), $\$ 150$ (\$198), and $\$ 225$ (\$376), which comprised $\$ 62$ (\$38), $\$ 125$ (\$75), and $\$ 155$ (\$80) for direct medical costs related to fibromyalgia and $\$ 58(\$ 0), \$ 24(\$ 0)$, and $\$ 70$ (\$0) for direct nonmedical costs for professional services for help with daily activities due to fibromyalgia among subjects with mild, moderate, and severe fibromyalgia, respectively.

fBased on subject-reported data. Lost productivity was assumed to cost $\$ 19.88$ per hour, and disability payments were assumed to be $\$ 1,004$ per month. Sources included the U.S. Department of Labor, Bureau of Labor Statistics 30 and Disability Payments. ${ }^{31}$

${ }^{8}$ Three-month costs were extrapolated from 4-week costs for absenteeism by multiplying 13 times the 4-week costs to capture an annualized cost and then dividing by 4 . Mean (median) 4-week costs related to absenteeism were $\$ 38(\$ 0), \$ 74(\$ 0)$, and $\$ 111(\$ 0)$ among subjects with mild, moderate, and severe fibromyalgia, respectively. Mean (SD) days missed from work for the past 4 weeks were 0.4 (0.9), 1.0 (1.4), and 3.0 (5.4) days for subjects with mild, moderate, and severe fibromyalgia, respectively.10

hBased on unit cost and subject-reported data. Unpaid informal care was assumed to cost $\$ 19.88$ per hour; 3-month costs for unpaid informal care were extrapolated from 4-week costs by multiplying 13 times the 4-week costs to capture an annualized cost and then dividing by 4. Mean (SD) 4-week hours related to unpaid informal care were 3.62 (7.03), 22.80 (100.27), and 35.38 (90.36) among subjects with mild, moderate, and severe fibromyalgia, respectively. 10

${ }^{i}$ Annualized costs were extrapolated from multiplying (a) 4 times the 3-month costs and (b) 13 times the 4-week costs.

$E R=$ emergency room; HRU = health care resource utilization; MPFS=Medicare physician fee schedule; $N A=$ not applicable; OPPS=outpatient prospective payment system; $S D=$ standard deviation 
physician office visits, diagnostic tests, hospitalizations, ER visits, and medications; (b) direct nonmedical costs incurred by subjects out-of-pocket for assistance with daily activities related to fibromyalgia; and (c) indirect costs for lost productivity of the subjects and/or associated with unpaid informal care. Taken together, the mean (median) total estimated 3-month direct and indirect costs of fibromyalgia were $\$ 2,555(\$ 1,759)$, $\$ 6,554(\$ 3,614)$, and $\$ 10,614(\$ 9,935)$ for patients with mild, moderate, and severe fibromyalgia, respectively; these costs differed significantly across fibromyalgia severity levels $(P<0.001$; Table 4). These 3-month costs correspond to mean (median) total annualized direct and indirect costs of $\$ 10,219(\$ 7,034)$, $\$ 26,217(\$ 14,454)$, and $\$ 42,456(\$ 39,740)$ for subjects with mild, moderate, and severe fibromyalgia, respectively.

Mean (median) total 3-month direct costs per subject were $\$ 1,213$ ( $\$ 1,150)$ for mild, $\$ 1,415$ ( $\$ 1,215)$ for moderate, and $\$ 2,329$ ( $\$ 1,760)$ for severe fibromyalgia; these were significantly different across fibromyalgia severity levels $(P=0.002$; Table 4). These 3-month costs correspond to mean (median) annualized total direct costs per subject of $\$ 4,854(\$ 4,600)$, $\$ 5,662$ ( $\$ 4,861)$, and $\$ 9,318(\$ 7,040)$ for mild, moderate, and severe fibromyalgia, respectively. Mean total direct costs accounted for $47.5 \%, 21.6 \%$, and $21.9 \%$ of mean total direct and indirect costs for subjects with mild, moderate, and severe fibromyalgia, respectively.

Mean (median) 3-month indirect costs were $\$ 1,341$ (\$0) for mild, $\$ 5,139$ ( $\$ 1,680)$ for moderate, and $\$ 8,285(\$ 7,030)$ for severe fibromyalgia; these costs increased significantly across fibromyalgia severity levels $(P<0.001$; Table 4$)$. These 3 -month costs correspond to mean (median) annualized indirect costs of $\$ 5,366(\$ 0), \$ 20,556(\$ 6,719)$, and $\$ 33,139$ (\$28,118) for mild, moderate, and severe fibromyalgia, respectively. Mean total indirect costs accounted for $52.5 \%, 78.4 \%$, and $78.1 \%$ of mean total direct and indirect costs for subjects with mild, moderate, and severe fibromyalgia, respectively.

\section{Sensitivity Analyses}

Sensitivity analyses were performed to test the impact of key study assumptions on annual direct and indirect costs per subject. First, an analysis of costs removing the top $1 \%$ of costs within each HRU category (physician visits, diagnostic tests, prescription medications, ER visits, professional services for daily activities, absenteeism, reduced work schedule, and lost productivity) was performed. Results remained significantly different across the 3 severity levels. Second, the prescribed medications to treat fibromyalgia were captured on the CRF; therefore, it is unknown if the subject filled the prescription. Thus, a sensitivity analysis was performed to determine the impact of a reduced prescription fill rate on annual direct costs per subject for each fibromyalgia severity level. The rates of unfilled prescriptions by drug class reported in the literature ${ }^{32}$ were applied in this analysis, and as a result, annual direct costs for subjects with mild, moderate, and severe fibromyalgia severity decreased by $\$ 99, \$ 80$, and $\$ 127$, respectively; significance did not change.

A third sensitivity analysis applied the 2009 minimum wage rate, ${ }^{33}$ rather than the average wage rate, to unpaid informal care. This analysis resulted in decreases in annual indirect costs per subject by $\$ 594, \$ 3,743$, and $\$ 5,808$ for subjects with mild, moderate, and severe fibromyalgia severity; significance did not change.

\section{Discussion}

This is the first study to evaluate both the direct and indirect costs of fibromyalgia by severity level from a U.S. patientcentric perspective. Consistent with previously published U.S. studies, ${ }^{6,12,13}$ this study demonstrated that fibromyalgia is associated with substantial direct and indirect costs to payers, patients, and society. This study also demonstrated that costs are higher for patients with worse fibromyalgia severity.

In the present study, as reported previously by Schaefer et al. (2011), subjects with fibromyalgia and a recent history of pain had a high number of comorbid conditions and were frequent users of health care services. ${ }^{10}$ Based on a medical record review of a 3-month period, we estimated that patients with mild, moderate, and severe fibromyalgia visited their physicians and other health care professionals (physical and massage therapists) on average 10.7, 20.9, and 27.7 times per year for fibromyalgia. Berger et al. (2007) estimated that fibromyalgia patients visited a physician an average of 17.8 times per year. ${ }^{15}$ White et al. (2008) estimated that fibromyalgia patients visited physicians 16.0 times per year and visited other health care professionals 12.0 times per year. ${ }^{12}$ In research performed by Robinson et al. (2003), patients with fibromyalgia were estimated to have an office service claim 11.9 times per year. ${ }^{13}$ Overall, the present study results are consistent with those of other studies that have documented high levels of HRU among patients with fibromyalgia ${ }^{6,12-15}$ and provide additional detail on how HRU differs across severity level.

Study physicians reported high HRU rates attributable to fibromyalgia, resulting in substantial total estimated direct medical costs per patient. During the 3 months prior to data collection, estimated mean direct medical costs (summing payer and patient out-of-pocket amounts for medical services) ranged from $\$ 1,025$ to $\$ 2,102$, representing annualized means of $\$ 4,101$ to $\$ 8,409$ per patient, depending on severity level. The major drivers of the direct medical costs were prescription medications and physician office visits. Subject-reported direct out-of-pocket medical costs for fibromyalgia accounted for $19.7 \%, 30.5 \%$, and $24.0 \%$ of total direct medical costs among subjects with mild, moderate, and severe fibromyalgia, respectively. These results are broadly consistent with those of 
other studies. For example, White et al. estimated total annual all-cause direct medical costs for fibromyalgia to be $\$ 7,286$ in 2005, with physician office visits and prescription drugs accounting for $19.6 \%$ and $22.4 \%$ of the total, respectively. ${ }^{12}$ Berger et al. estimated mean annual all-cause direct medical costs for fibromyalgia to be $\$ 9,573$ in 2004 and $2005 .{ }^{15}$

In this study, estimates of mean annualized indirect costs related to lost productivity were higher than previous estimates in the United States ${ }^{12,13,34}$ but include a more comprehensive assessment of indirect costs compared with previous research. For example, in addition to collecting data on the time missed from work, this study collected data on lost productivity due to disability, unemployment, early retirement, or reduced work schedule, as well as lost productivity related to fibromyalgia subjects' informal care as published previously by Schaefer et al. ${ }^{10}$ The present study evaluated lost productivity among working-age adults. The indirect costs related to lost productivity for patients and/or caregivers accounted for a little more than one-half $(52.5 \%)$ of total costs for subjects with mild fibromyalgia but more than three-quarters of total costs for those with moderate $(78.4 \%)$ and severe (78.1\%) fibromyalgia. These findings are similar to those reported for several other countries. Winkelmann et al. (2011) used a similar methodology and estimated that more than three-quarters of total fibromyalgiarelated societal costs in France (88.5\%) and Germany (75.7\%) were attributable to fibromyalgia-related lost productivity and disability. ${ }^{16}$

In the present study, absenteeism and disability, the 2 drivers of indirect costs most often studied in other research, comprised $9.2 \%, 25.9 \%$, and $43.1 \%$ of total indirect costs among mild, moderate, and severe fibromyalgia subjects. Additionally, among those unemployed, $41.9 \%, 28.6 \%$, and $0.0 \%$ of subjects with severe, moderate, and mild fibromyalgia, respectively, reported being disabled due to fibromyalgia. Kleinman et al. (2009) also noted substantial absenteeism; employed fibromyalgia patients in their claims analyses missed an average of 16.8 days of work annually, representing $20.6 \%$ of total costs. ${ }^{35}$ White et al. reported that on average employees with fibromyalgia missed 29.8 days of work per year due to disability and medical reasons, and employer disability payments and imputed medically related absenteeism accounted for nearly one-third of total costs. ${ }^{12}$ Robinson et al. also found that a substantial portion (32.5\%) of total costs for fibromyalgia was due to work disability claims; the prevalence of a disability claim was twice as high among employees with fibromyalgia when compared with the overall employee population. ${ }^{13}$

Costs associated with informal care due to fibromyalgia also were substantial in the present study. Based on a 4-week reporting period, study subjects with mild, moderate, and severe fibromyalgia, respectively, reported annualized mean costs of $\$ 935, \$ 5,891$, and $\$ 9,143$, respectively, for lost productivity and unpaid informal care from one or more caregivers due to fibromyalgia.
Although presenteeism was not quantified in the present study's calculation of total costs, previously published study results suggest that presenteeism likely contributes substantially to the economic burden of fibromyalgia. Schaefer et al. reported that employed study subjects with mild, moderate, and severe fibromyalgia worked with fibromyalgia symptoms for annualized averages of 89, 199, and 252 days per year and reported working at lower levels of effectiveness when experiencing such symptoms. ${ }^{10}$ This aspect of the present study findings should be explored in future research.

\section{Limitations}

The foremost limitation of this study is the possibility of selection bias because subjects were recruited from among fibromyalgia patients seeking care during a routine office visit who met a number of inclusion criteria, including a prior diagnosis of fibromyalgia by a rheumatologist or pain specialist. We did not record either the total number of patients screened or the counts of those excluded by each sampling exclusion criterion. The proportion of subjects categorized as having severe fibromyalgia in the present study (65.5\%) may have been higher than would be expected by normal distribution patterns (i.e., in a random probability sample) because we required subjects to have experienced widespread pain in the previous 3 months and pain in the 24 hours before enrollment, potentially excluding subjects with milder fibromyalgia. Therefore, we presented results for each severity group individually because combined results across severity levels from the present study may not be generalizable to the overall fibromyalgia population in the United States.

Second, the study was cross-sectional and based on a retrospective review of medical records to identify HRU. Physician attributions of HRU due to fibromyalgia were not verified and could have been over- or underestimated. Additionally, subjects might potentially have incomplete records. For example, visits to other physicians or health care providers might not have been recorded in the records at the study site, or the chart may not have captured services or procedures performed at other facilities. In particular, since the study was performed in the community-based physician office setting, HRU related to hospital care and ER visits may have been under-reported. Similarly, medications prescribed were captured on the CRF, but the CRF may not have included all medications prescribed, for example, by a nonstudy physician, and did not capture whether subjects filled their prescriptions; therefore, true utilization of medications may not have been measured.

Third, actual costs were not determined in this study; by assigning Medicare fees to physician's visits, this study may have underestimated the real cost of a visit because physicians may charge higher fees than the Medicare scale. Fourth, costs were annualized from a retrospective chart review based on a 3-month time period, and self-reported costs from the 


\section{The Comparative Economic Burden of Mild, Moderate, and Severe Fibromyalgia: Results from a Retrospective Chart Review and Cross-Sectional Survey of Working-Age U.S. Adults}

patient-reported data were based on a 4-week recall period. Additionally, patient reports of direct out-of-pocket costs for HRU, direct nonmedical costs for paid assistance with daily activities, lost work hours, and informal care could not be verified. This method may have led to over- or underestimation of actual annual costs.

Fifth, while our study captured many indirect costs, some indirect costs were not captured, such as subsidized transportation costs for the disabled. The costs assigned to reported lost productivity were based on assumptions. Consequently, indirect costs may have been over- or underestimated. Sixth, we did not collect data on matched comparison group cases without a diagnosis for fibromyalgia and cannot compare our costs with those of such patients. Finally, the study applied probability statistical testing procedures to results obtained from a nonprobability convenience sample. Because the sample does not necessarily reflect the sampling distribution, statistical test results may not be accurate for extrapolation to the population. Further research using larger probability samples would be helpful to confirm findings.

The strength of this study was that detailed information was collected directly from the patient, which enabled more comprehensive quantification of costs due to fibromyalgia. However, subjective bias might have led to over- or underestimation of certain patient-reported variables, such as out-ofpocket expenditures and time missed from work.

\section{Conclusions}

This is the first U.S. study to examine both fibromyalgia-related direct costs related to HRU and fibromyalgia-related indirect costs due to lost productivity and informal care by fibromyalgia severity level. Both direct and indirect costs related to fibromyalgia are higher among subjects with worse fibromyalgia severity. Indirect costs account for the majority of fibromyalgiarelated costs at all fibromyalgia severity levels.

\section{Authors}

ARTHI CHANDRAN, MS, MPH, is Associate Director, and GERGANA ZLATEVA, PhD, is Senior Director, Pfizer Inc., New York, New York. CAROLINE SCHAEFER, MBA, is Vice President; KELLIE RYAN, MPH, was Senior Associate at the time of the study; and REBECCA BAIK, BS, is Senior Analyst, Covance Market Access Services, Inc., Gaithersburg, Maryland. At the time of the study, MICHAEL MCNETT, MD, was Physician, APAC Centers for Pain Management, Chicago, Illinois. He is currently Director, Aurora West Allis Pain Program, West Allis, Wisconsin.

AUTHOR CORRESPONDENCE: Caroline Schaefer, MBA, Covance Market Access Services, Inc., 9801 Washingtonian Blvd., 9th Fl., Gaithersburg, MD 20878. Tel.: 240.632.3000; E-mail: Caroline.Schaefer@covance.com.

\section{DISCLOSURES}

This study was funded by Pfizer Inc. Chandran and Zlateva are employees of Pfizer, Inc. Schaefer, Ryan, and Baik were paid consultants to Pfizer Inc. during the conduct of this study and in connection with the development of this article.

Chandran, Schaefer, and Zlateva had primary responsibility for study concept and design, assisted by Ryan. Ryan and Schaefer had primary responsibility for data collection with the assistance of staff at each of the participating study sites. All authors, along with acknowledged contributors Goldenberg, Anastassopoulos, and Gerwin contributed to data interpretation. Baik, Schaefer, and Ryan wrote the original manuscript with the assistance of acknowledged contributor Hufstader. All authors and acknowledged contributors Goldenberg and Gerwin contributed substantively to the revision of the manuscript.

\section{ACKNOWLEDGEMENTS}

We would like to thank Don Goldenberg, MD, and Robert Gerwin, MD, for their guidance and assistance with the analysis and preparation of the manuscript. Additionally, we would like to thank Meghan Hufstader, PhD; Kathryn Anastassopoulos, MS; and Shoshana Daniel, PhD, employees of Covance Market Access Services, and Da-In Kim, MPH, a research associate with Pfizer Inc., for their support with the analysis. We also thank the investigators who participated in this study: Dr. John Peniston, Dr. Gary Bedel, Dr Jeffrey Rosen, Dr. Judith Kirstein, Dr. Jay Fawver, Dr. Don Goldenberg, Dr. Alan Kivitz, Dr. Michael Hassman, Dr. Dana Trotter, Dr. Lawrence Ginsberg, Dr. Steven Katz, Dr. Ara Dikranian, Dr. Michael McNett, Dr. Angela Stupi, Dr. Robert Gerwin, Dr. Jan Brandes, Dr. Paul Gross, Dr. Standiford Helm, Dr Alan Lichtbroun, and Dr. Shahram Jacobs.

\section{REFERENCES}

1. Wolfe F, Ross K, Anderson J, Russell IJ, Hebert L. The prevalence and characteristics of fibromyalgia in the general population. Arthritis Rheum. 1995;38(1):19-28

2. Wolfe F, Smythe HA, Yunus MB, et al. The American College of Rheumatology 1990 Criteria for the Classification of Fibromyalgia. Report of the Multicenter Criteria Committee. Arthritis Rheum. 1990;33(2):160-72.

3. Berger A, Sadosky A, Dukes E, Martin S, Edelsberg J, Oster G. Characteristics and patterns of healthcare utilization of patients with fibromyalgia in general practitioner settings in Germany. Curr Med Res Opin. 2008;24(9):2489-99.

4. Boonen A, van den Heuvel R, van Tubergen A, et al. Large differences in cost of illness and wellbeing between patients with fibromyalgia, chronic low back pain, or ankylosing spondylitis. Ann Rheum Dis. 2005;64(3):396402. Available at: http://www.ncbi.nlm.nih.gov/pmc/articles/PMC1755408/ pdf/v064p00396.pdf. Accessed July 72012

5. Hughes G, Martinez C, Myon E, Taieb C, Wessely S. The impact of a diagnosis of fibromyalgia on health care resource use by primary care patients in the UK: an observational study based on clinical practice. Arthritis Rheum. 2006;54(1):177-83. Available at: http://onlinelibrary.wiley.com/doi/10.1002/ art.21545/pdf. Accessed July 7, 2012.

6. White LA, Robinson RL, Yu AP, et al. Comparison of health care use and costs in newly diagnosed and established patients with fibromyalgia. J Pain. 2009;10(9):976-83.

7. Annemans L, Le Lay K, Taïeb C. Societal and patient burden of fibromyalgia syndrome. Pharmacoeconomics. 2009;27(7):547-59.

8. Bennett RM, Jones J, Turk DC, Russell IJ, Matallana L. An internet survey of 2,596 people with fibromyalgia. BMC Musculoskeletal Disord. 2007;8:27. Available at: http://www.biomedcentral.com/1471-2474/8/27. Accessed July 7, 2012 


\section{The Comparative Economic Burden of Mild, Moderate, and Severe Fibromyalgia: Results from a Retrospective Chart Review and Cross-Sectional Survey of Working-Age U.S. Adults}

9. Bigatti SM, Hernandez AM, Cronan TA, Rand KL. Sleep disturbances in fibromyalgia syndrome: relationship to pain and depression. Arthritis Rheum 2008;59(7):961-67. Available at: http://onlinelibrary.wiley.com/doi/10.1002/ art.23828/full. Accessed July 7, 2012

10. Schaefer C, Chandran A, Hufstader M, et al. The comparative burden of mild, moderate and severe fibromyalgia: results from a cross-sectional survey in the United States. Health Qual Life Outcomes. 2011;9:71. Available at: http://www.hqlo.com/content/9/1/71. Accessed July 7, 2012.

11. Perrot S, Winkelmann A, Dukes E, et al. Characteristics of patients with fibromyalgia in France and Germany. Int J Clin Pract. 2010;64(8):1100-08.

12. White LA, Birnbaum HG, Kaltenboeck A, Tang J, Mallet D, Robinson RL. Employees with fibromyalgia: medical comorbidity, healthcare costs, and work loss. J Occup Environ Med. 2008;50(1):13-24. Available at: http:// www.analysisgroup.com/uploadedFiles/Publishing/Articles/JOEM_ Employees_With_Fibromyalgia.pdf. Accessed July 7, 2012.

13. Robinson RL, Birnbaum HG, Morley MA, Sisitsky T, Greenberg PE, Claxton AJ. Economic cost and epidemiological characteristics of patients with fibromyalgia claims. J Rheumatol. 2003;30(6):1318-25.

14. Wolfe F, Anderson J, Harkness D, et al. A prospective, longitudinal, multicenter study of service utilization and costs in fibromyalgia. Arthritis Rheum. 1997;40(9):1560-70.

15. Berger A, Dukes E, Martin S, Edelsberg J, Oster G. Characteristics and healthcare costs of patients with fibromyalgia syndrome. Int J Clin Pract. 2007:61(9):1498-508. Available at: http://www.ncbi.nlm.nih.gov/pmc/articles/PMC2040193/. Accessed July 7, 2012.

16. Winkelmann A, Perrot S, Schaefer C, et al. Impact of fibromyalgia severity on health economic costs: results from a European cross-sectional study. Appl Health Econ Health Policy. 2011;9(2):125-36.

17. Goldenberg DL, Burckhardt C, Crofford L. Management of fibromyalgia syndrome. JAMA. 2004;292(19):2388-95. Available at: http://jama.ama-assn. org/content/292/19/2388.full.pdf+html. Accessed July 7, 2012.

18. Sinclair D, Starz TW, Turk DC. The manual tender point survey. National Fibromyalgia Association. Reprinted from FMOnline. October 3, 2005. Available at: http://www.fmaware.org/News2eb58.html?page=News Article\&id=6263. Accessed July 7, 2012.

19. No authors listed. EuroQol-a new facility for the measurement of health related quality of life. The EuroQol Group. Health Policy. 1990; 16(3):199-208.

20. Burckhardt CS, Clark SR, Bennett RM. The Fibromyalgia Impact Questionnaire: development and validation. J Rheumatol. 1991;18(5):728-33.

21. Belza BL, Henke CJ, Yelin EH, Epstein WV, Gilliss CL. Correlates of fatigue in older adults with rheumatoid arthritis. Nurs Res. 1993;42(2):93-99.

22. Hays RD, Stewart AL. Sleep measures. In: Stewart AL, Ware JE, eds. Measuring Functioning and Well-Being: The Medical Outcomes Study Approach. Durham, NC: Duke University Press; 1992:235-59.
23. Zigmond AS, Snaith RP. The hospital anxiety and depression scale. Acta Psychiatr Scand. 1983;67(6):361-70.

24. Bennett R. The Fibromyalgia Impact Questionnaire (FIQ): a review of its development, current version, operating characteristics and uses. Clin Exp Rheumatol. 2005;23(5 Suppl 39):S154-S62. Available at: http://www.necksolutions.com/The-Fibromyalgia-Impact-Questionnaire.pdf. Accessed July 7, 2012.

25. Bennett RM, Bushmakin AG, Cappelleri JC, Zlateva G, Sadosky AB. Minimal clinically important difference in the fibromyalgia impact questionnaire. J Rheumatol. 2009;36(6):1304-11.

26. U.S. Department of Health and Human Services, Centers for Medicare \& Medicaid Services. Medicare physician fee schedule for CY 2009. 42 CFR Parts 405 and 409. Final rule. Federal Register, November 19, 2008:6972570237.

27. U.S. Department of Health and Human Services, Centers for Medicare $\&$ Medicaid Services. 2009 Medicare hospital outpatient prospective payment system. 42 CFR Parts 410, 416, and 419. Final rule. Federal Register, November 18, 2008:68501-69380.

28. U.S. Department of Health and Human Services. Report to the President: prescription drug coverage, spending, utilization, and prices. Chapter 3: Prescription drug prices. April 2000. Available at: http://aspe. hhs.gov/health/reports/drugstudy/chap03.htm. Accessed July 7, 2012.

29. ReadyPrice [CD-ROM]. Version 2009:4. New York, NY: Thomson Reuters; 2009.

30. National Bureau of Labor Statistics. National Compensation Survey: occupational earnings in the United States, 2007. Table 1. Available at: http://www.bls.gov/ncs/ncswage2007.htm\#Wage_Tables. Accessed July 7, 2012.

31. Social Security Administration. Fast facts \& figures about Social Security. SSA Publication No. 13-11785. August 2008. Available at: http:// www.socialsecurity.gov/policy/docs/chartbooks/fast_facts/2008/fast_facts08. pdf. Accessed July 7, 2012.

32. Kennedy J, Tuleu I, Mackay K. Unfilled prescriptions of medicare beneficiaries: prevalence, reasons, and types of medicines prescribed. J Manag Care Pharm. 2008;14(6):553-60. Available at: http://www.amcp.org/data/jmcp/ jmcpmaga_553-560.pdf.

33. U.S. Department of Labor. Wages and hours worked: minimum wage. Available at: http://www.dol.gov/compliance/topics/wages-minimum-wage. htm. Accessed July 7, 2012.

34. Evans CJ, Parthan A, Le K. Economic and humanistic burden of fibromyalgia in the USA. Expert Rev Pharmacoecon Outcomes Res. 2006;6(3):303-14.

35. Kleinman N, Harnett J, Melkonian A, Lynch W, Kaplan-Machlis B, Silverman SL. Burden of fibromyalgia and comparisons with osteoarthritis in the workforce. J Occup Environ Med. 2009;51(12):1384-93. 